Available online at GSC Online Press Directory

GSC Biological and Pharmaceutical Sciences

e-ISSN: 2581-3250, CODEN (USA): GBPSC2

Journal homepage: https://www.gsconlinepress.com/journals/gscbps

(RESEARCH ARTICLE)

\title{
Adsorption of phenol onto unactivated Moringa oleifera Seed Shells residue by UV - visible spectrophotometer
}

\author{
Daniel Eneji Sani ${ }^{1,}{ }^{*}$, John O. Idoko ${ }^{2}$, Enyojo Samson Okwute ${ }^{3}$ and Matthew Chijioke Apeh ${ }^{4}$ \\ ${ }^{1}$ Department of Plant Science and Biotechnology, Kogi State University, Kogi- Nigeria. \\ 2 Department of Pure and Industrial Chemistry, Bayero University Kano-Nigeria. \\ ${ }^{3}$ Department of Pure and Applied Chemistry, University of Maiduguri. Borno-Nigeria. \\ ${ }^{4}$ Department of Plant science and Biotechnology, University of Nigeria. Enugu-Nigeria.
}

Publication history: Received on 03 November 2020; revised on 09 November 2020; accepted on 11 November 2020

Article DOI: https://doi.org/10.30574/gscbps.2020.13.2.0354

\begin{abstract}
Unactivated adsorbent was prepared from Moringa oleifera seed shells precursor, characterized and evaluated for aqueous phase removal of phenol. The effects of operational parameters such as initial phenolic solution $\mathrm{pH}$ and adsorbent dosage on equilibrium sorption were studied. Adsorption isotherms and kinetic experiments performed at $\left(25{ }^{\circ} \mathrm{C}\right)$ furnished some equilibrium and kinetic parameters, respectively. UAMSS shows favorable attributes on $(\mathrm{pH}$, bulk density, attrition, iodine number/surface area, surface charge/functional groups and Fourier transform infrared FTIR). Phenol uptake decreases with increase in solution $\mathrm{pH}$ for the adsorbent. Maximum adsorption capacity $\mathrm{Q}_{\max }$ (mg/g) was (6.95). The optimal pH for phenol adsorption was attained at pH 3, adsorption kinetics obeyed closely pseudo-second-order model. Adsorption of phenol was well described by Langmuir isotherm. The adsorbent shows a promise of applicability in dephenolation of aqueous effluents/wastewater.
\end{abstract}

Keywords: Phenol; Moringa Oleifera Seed Shells; Adsorption Isotherms; Kinetics; Wastewater Remediation

\section{Introduction}

The increase in world population and intensification of industrial activities has made the field of environmental pollution and other environmental problems key subjects of concern. There has been a huge increase in the manufacture and use of synthetic chemicals since the beginning of the 20th century, which may lead to chemical contamination; these include wastes from industrial chemicals production, metal plating operations, pesticide run off from agricultural lands, and other industrial applications and productions [1]. All industries use specific chemicals or other raw materials to produce their final products. Production usually involves many steps and processes, and each process is capable of producing hazardous wastes. A waste is considered hazardous if it is reactive, ignitable, corrosive or toxic [2]. Phenolics and other organic compounds in water are derived from the natural decomposition of plant and animal materials, from industrial, urban, or agricultural pollutants and, from the reaction of halides (most often chlorine) with natural organics during water treatment. Concentrations range from zero in protected ground waters to $10-30 \mathrm{mg} / \mathrm{L}$ in contaminated surface water. Phenol, as an aromatic semi volatile hydrocarbon, is commonly present in waters, wastewaters of most industries such as high temperature coal conversion, petroleum refining, resin and plastic, leather and textile manufacturing [3]. Oil refineries, chemical plants, coke ovens, aircraft maintenance, laundry operations, paperprocessing plants, paint manufacturing, rubber reclamation plants, nitrogen works, and fiberglass manufacturing in different ranges from $1 \mathrm{mg} / \mathrm{L}$ to $7000 \mathrm{mg} / \mathrm{L}$.

\footnotetext{
* Corresponding author: Daniel Eneji Sani

Department of Plant Science and Biotechnology, Kogi State University, Kogi- Nigeria. 
Phenol constitutes 11 th of the 126 chemicals which have been pointed as priority pollutants according to United States Environmental Protection Agency [4]. In fact, the adverse effects of phenol have been observed on the central nervous system, cardiovascular system as well as urino-genital systems of human being, often expressed by multiple symptoms: convulsions, coma, cardiac disorders, respiratory failure and collapse [5]. The various methods for removal of phenol from wastewater include steam stripping, solvent extraction, and oxidation, ion exchange, biodegradation and adsorption methods [6]. Out of all these, adsorption methods are the most-widely used techniques and activated carbon has been the predominant adsorbent all over the world [7].

However, due to its high cost and low regeneration capacity, since the last three decades, extensive research has been directed towards investigating the adsorption characteristics and potentials of cheaper materials and solid wastes, such as fly ash, maize cob, peat, soil, rice husk, sawdust, orange peel and so on $[2,8]$. The specific objectives of this study are to: (i) prepare and characterize physicochemical properties of adsorbents from locally sourced precursor - Moringa oleifera seed shells (ii) assess the intensity of the adsorbent to remove phenol from aqueous phase under the effects of different initial phenolic solution $\mathrm{pH} /$ concentration, adsorbent dose, contact time and temperature. (iii) Evaluate the adsorption process in terms of isothermal variables, equilibrium and kinetics.

\section{Adsorption experiment}

\subsection{Material and methods}

Phenol $\left(\mathrm{C}_{6} \mathrm{H}_{5} \mathrm{OH} ; \mathrm{MW}=94 \mathrm{~g} \mathrm{~mol}^{-1}\right.$, PARK scientific Ltd UK; aqueous solubility $\left.=8.2 \% ; \lambda_{\max }=270\right)$, sodium hydroxide $(\mathrm{NaOH})$, sodium carbonate $\left(\mathrm{Na}_{2} \mathrm{CO}_{3}\right)$, sodium thiosulphate $\left(\mathrm{Na}_{2} \mathrm{~S}_{2} \mathrm{O}_{3} .5 \mathrm{H}_{2} \mathrm{O}\right)$, potassium iodate ( $\left.\mathrm{KIO}_{3}\right)$, iodine crystals (I) Sulphuric acid $\left(\mathrm{H}_{2} \mathrm{SO}_{4}\right)$, Hydrochloric acid $(\mathrm{HCl}) \mathrm{BDH}$ chemicals limited England, sodium hydrogen carbonate $\left(\mathrm{NaHCO}_{3}\right)$ Griffin \& George scientific wembly UK, potassium iodide (KI) Burgoyne and co India, Instrument include Fourier Transform Infrared spectrophotometer (FTIR-8400S Shimadzu Japan), UV-visible spectrophotometer (Jenway6405UV, Japan), analytical weighing balance (Adam Equipment Co, Ltd US), muffle furnace (Carbolite, UK), mechanical shaker (Heldolp Unimax 2010, Germany), thermostatic water bath (Clifton, UK).

\subsection{Preparation and characterization of adsorbent}

Moringa oleifera seeds were purchased from the Kaduna central Market, Kaduna state northwest Nigeria located on Latitude $11^{\circ} 10^{\prime} \mathrm{N}$ and longitude $7^{\circ}$ 38' E. The seeds were deshelled and the shells washed with tap water followed by distilled water to remove dirt and air-dried. The adsorbent was further characterized physicochemically. Adsorbent $\mathrm{pH}$ was determined by dispersing 1.0-g triplicate samples of the adsorbent for 4 hour and measuring the $\mathrm{pH}$ of the resulting filtrate [9]. Bulk density was determined by the tamping procedure of [10]. Attrition was determined by a procedure described by [10]. Adsorbent surface area was determined by the iodine adsorption number method during which, a 1.0-g portion of the adsorbent was slurried with an excess of standard iodine solution followed by back-titration of the unreacted iodine with standard sodium thiosulphate solution [11]. A blank titration was also performed on an aliquot of iodine solution not treated with the adsorbent. The iodine number, $n_{\mathrm{I}_{2}}$ (i.e., amount in moles of iodine adsorbed per g adsorbent) was calculated using equation 1; while the adsorbent surface area, $A\left(\mathrm{~m}^{2} \mathrm{~g}^{-1}\right)$ was calculated with the aid of equation 2 , a modified form of that of [11].

$$
\begin{aligned}
& n_{\mathrm{I}_{2}}\left(\mathrm{~mol} \cdot \mathrm{g}^{-1}\right)=\frac{C_{\mathrm{S}_{2} \mathrm{O}_{3}{ }^{2-}}\left(V_{\mathrm{b}}-V_{\mathrm{s}}\right)}{2 \times 10^{3} m_{\mathrm{a}}} \\
& A\left(\mathrm{~m}^{2} \cdot \mathrm{g}\right)=N_{\mathrm{o}}\left[\frac{C_{\mathrm{S}_{2} \mathrm{O}_{3}{ }^{2-}}\left(V_{\mathrm{b}}-V_{\mathrm{s}}\right)}{2 \times 10^{3} m_{\mathrm{a}}}\right] \sigma_{\mathrm{I}_{2}}
\end{aligned}
$$

where $C_{\mathrm{S}_{2} \mathrm{O}_{3}{ }^{2-}}$ is the concentration of the thiosulphate $\left(\mathrm{mol} \mathrm{L}^{-1}\right) ; V_{\mathrm{b}}$ and $V_{\mathrm{s}}$ are respectively, the titre values of the blank and adsorbent-treated iodine solutions (L); $m_{\mathrm{a}}$ is mass of the adsorbent used (1.0 g); $N_{\mathrm{o}}$ is the Avogadro's number; and $\sigma_{\mathrm{I}_{2}}$ is the cross-sectional area of an iodine molecule $\left(\mathrm{m}^{2}\right)$, given as $3.2 \times 10^{-19} \mathrm{~m}^{2}$. Titratable surface charge was determined by the Boehm titrimetric method described by Van Winkle. Fourier transformed infrared (FTIR) analysis was performed according to the manufacturer's specifications. 


\subsection{Formation of calibration curves}

A $3 \mathrm{~mL}$ of the stock $(1000 \mathrm{mg} / \mathrm{L})$ phenolic solution was put in the cuvet and placed on the UV spectrophotometer. The machine was scanned and the wavelength of maximum absorption $(\lambda \max =270 \mathrm{~nm})$ was noted. Next, working standard phenolic solutions $(20,40,60,80$ and $100 \mathrm{mg} / \mathrm{L})$ were prepared by serial dilution of the stock (1000 mg/L). A plot of absorbance versus concentration furnished the calibration curve $(A=0.013 \mathrm{Ce} ; \mathrm{R} 2=0.999)$ from which the concentration of phenol in real samples were calculate

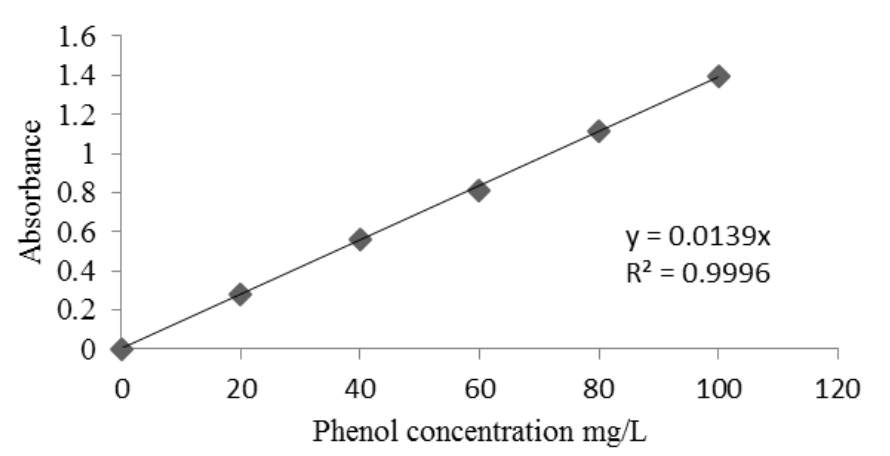

Figure 1 Calibration curve for UV-Visible Spectrophometric determination of phenol in aqueous solution $\left(\lambda_{\max }=270\right.$ $\mathrm{nm}$ )

\subsection{Batch adsorption experiments}

Standard phenolic solutions $(0-100 \mathrm{mg} / \mathrm{L})$ were prepared by serially diluting appropriate volumes of the stock (1000 $\mathrm{mg} / \mathrm{L}$ ) using distilled water. The effect of solution $\mathrm{pH}$ on phenol adsorption was studied by treatment of 50-mL aliquots of phenolic solution adjusted to different $\mathrm{pH}(3,5,7,9$ and 11) with 0.5-g of the adsorbents for 4 hour at laboratory temperature $\left(25^{\circ} \mathrm{C}\right)$. The effect of adsorbent dosage was investigated by contacting different masses $(0.5,1.0,1.5,2.0$ and $2.5 \mathrm{-g}$ ) of the adsorbents with $50 \mathrm{~mL}$ of the phenolic solution at a given $\mathrm{pH}$. Adsorption isotherms were developed at temperatures $\left(25^{\circ} \mathrm{C}\right)$ by dispersing separate 0.5 -g portions of the adsorbents in 50 -mL aliquots of each standard $(0-$ $100 \mathrm{mg} / \mathrm{L}$ ) phenolic solution with the aid of a mechanical shaker for 4 hour.

Adsorption kinetic experiments were performed by contacting 0.5 -g portions of the adsorbents dispersed with 50 -mL aliquots of $100 \mathrm{mg} / \mathrm{L}$ phenolic solutions $10,30,60,120,180$ and $240 \mathrm{~min}$ on a shaker at $\left(25^{\circ} \mathrm{C}\right)$. Residual phenol concentrations in the solutions before and after adsorption were measured using a UV spectrophotometer following the manufacturer's specification. In all cases, the amount of phenol adsorbed per gram of adsorbents, $Q_{\mathrm{e}}$ (mg/g) and removal efficiency, $R E(\%)$ were calculated using Equation (3) and (4), respectively.

$$
\begin{aligned}
& Q(\mathrm{mg} / \mathrm{g})=\frac{\left(C_{\mathrm{o}}-C\right) V}{m_{\mathrm{a}}} \\
& \operatorname{RE}(\%)=\left(\frac{C_{o}-C}{C_{o}}\right) \times 100
\end{aligned}
$$

where $C_{\mathrm{o}}$ and $C$ are the initial and residual phenol concentrations $(\mathrm{mg} / \mathrm{L})$, respectively, $V$ is the aliquot of phenol solution used (L); and $m_{\mathrm{a}}$ is the mass of adsorbent $(\mathrm{g})$ used for a particular batch treatment.

\section{Results and discussion}

\subsection{Physicochemical parameters of adsorbent}

Some physicochemical characteristics of the experimental adsorbent is recorded in Table 1 . And Figure 2 represent the FTIR spectra of un-activated adsorbent. The UAMSS had pH of 4.6. This value is within the range recorded for activated carbons from olive stones and walnut shells [22]. The bulk density (kg/m3) for UAMSS is 354.0 \pm 2.5 ; this value is higher than the minimum requirement of $(0.25 \mathrm{~g} / \mathrm{mL})$ for application on the removal of pollutants from waste water [23]. Attrition Loss analysis provides us with valuable information on UAMSS for phenol removal. High attrition losses 
indicate that the adsorbents may be less effective and more expensive due to frequency of maintenance and purchase of addition material. However, it is important to consider the coefficient of uniformity, which indicates the range of particle sizes [24] the result shows that adsorbent UAMSS have acceptable attrition loss after preparation, hence are good sources of materials for adsorbent preparation. The iodine number indicates the extent of microspores volume distribution within the adsorbent matrices, hence the surface area. The iodine number (mol/g)/surface areas (m2/g) $7.1 \times 10-4 \pm 0.0$ and $159.9 \pm 3.5$ for UAMSS, the surface charge are within the range $(150-500 \mathrm{~m} 2 / \mathrm{g}) \mathrm{required}$ for wastewater treatment and removal of small molecules from aqueous solution [22].

Table 1 Selected Physicochemical Characteristics of un-activated Adsorbent from Moringa oleifera Seed Shells

\begin{tabular}{|l|l|}
\hline Characteristic & UAMSS \\
\hline $\mathrm{pH}$ & $4.6 \pm 0.0$ \\
\hline Bulk density $\left(\mathrm{kg} \cdot \mathrm{m}^{-3}\right)$ & $354.0 \pm 2.5$ \\
\hline Attrition (\%) & $29.0 \pm 3.0$ \\
\hline Iodine number $\left(\mathrm{mol.g}^{-1}\right)$ & $7.1 \times 10^{-4} \pm 0.0$ \\
\hline Surface area $\left(\mathrm{m}^{2} \cdot \mathrm{g}^{-1}\right)$ & $159.9 \pm 3.5$ \\
\hline Surface charge $\left(\mathrm{mmol} \mathrm{H}^{+}\right.$eq.g \\
\end{tabular}

Titratable surface charge acidic groups (mmol H+ eq/g) were determined by the neutralizing with series of bases of varying strength: $\mathrm{NaOH}, \mathrm{NaHCO} 3$ and Na2CO3. The order of acidic groups on the surfaces of UAMSS was lactones, carboxylic and phenolic other oxygen based acidic functional groups which may be found on the adsorbent surface include carbonyls, anhydrides, ethers and hydroxyl [9, 23]

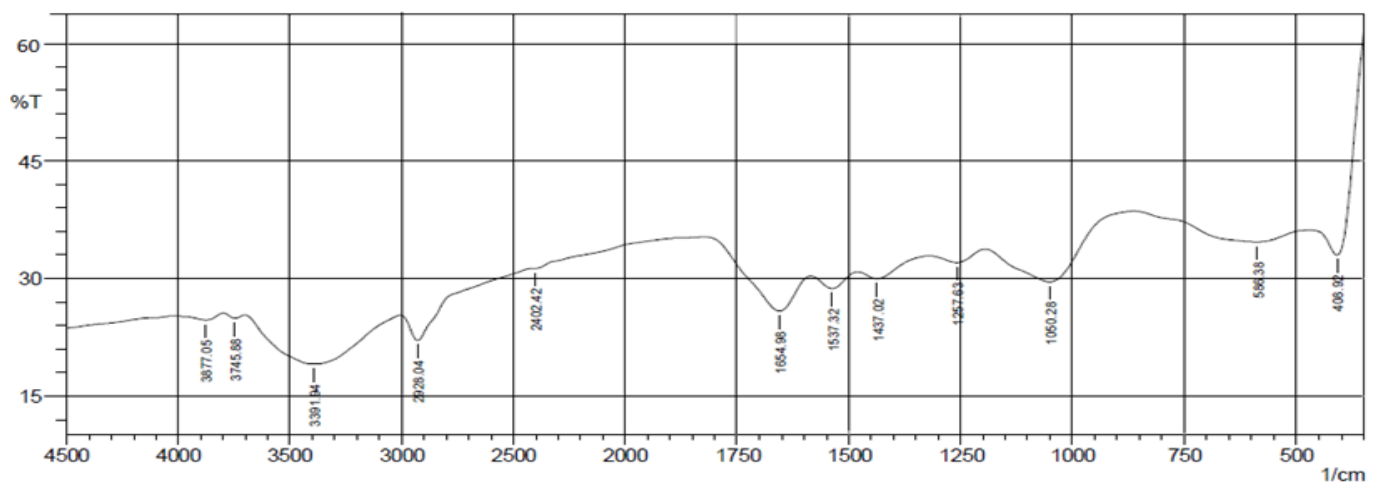

Figure 2 Fourier Transform Infrared (FTIR) spectra of un-activated Moringa oleifera seed shells

FTIR analysis played important role in identify the characteristic functional groups on the adsorbent surface. The FTIR spectra of the adsorbent Moringa oleifera as shown in Figure 2 .The FTIR analysis permitted spectrophotometric observation of the UAMSS surfaces in the range of $4500-500 \mathrm{~cm}^{-1}$ and serve as a direct means for the identification of the surface functional groups. The broad adsorption bands at $3391 \mathrm{~cm}^{-1}$ assigned to the $-\mathrm{OH}$ and $-\mathrm{NH}$ stretching vibrations of hydroxyl groups and primary and secondary amides [12]. The band at $2928 \mathrm{~cm}^{-1}$ is due to $0-\mathrm{H}$ hydrogen bonded groups of the aromatic. $\mathrm{C}=\mathrm{C}$ and $\mathrm{C}-\mathrm{H}$. Absorptions occur between $1437 \mathrm{~cm}^{-1}$ indicating the presence of Alkane, alkenes [13]. The band $1257 \mathrm{~cm}^{-1}$ is due to $-\mathrm{NH}$ primary and secondary amines and amides. The band at $1050 \mathrm{~cm}^{-1}$ is due to $\mathrm{C}-\mathrm{O}$ vibration in $\mathrm{C}-\mathrm{OH}$. These changes observed in the spectrum indicated the possible involvement of these functional groups on the surface of the adsorbent in sorption process. 


\subsection{Effect Initial Solution pH on Phenol Removal}

The adsorption capacity is influenced most by the $\mathrm{pH}$ of the solution. The $\mathrm{pH}$ of the solution primarily affected the surface charge of the adsorbents UAMSS degree of ionisation and speciation of the phenol species in the study, which may lead to change in kinetics and equilibrium characteristics phenol removal process [13]. The effect of initial solution $\mathrm{pH}$ (Figure 4) was investigated over the $\mathrm{pH}$ ranges of 3 - 11 with the initial concentration of phenol fixed at $100 \mathrm{mg} / \mathrm{L}$. The amount of phenol decreases with increasing $\mathrm{pH}$ for UAMSS. The highest phenol uptakes: UAMSS (8.3 mg/g) and was recorded at pH 3; while the least UAMSS $(1.81 \mathrm{mg} / \mathrm{g})$ was achieved at pH 11.

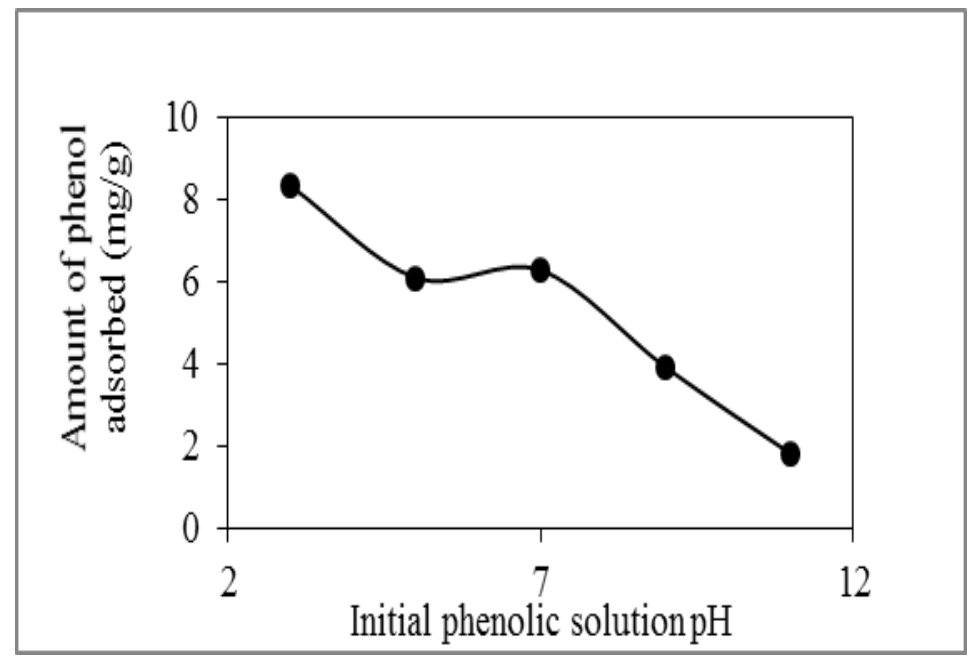

Figure 3 Effect initial solution pH on phenol adsorption onto un-activated adsorbent UAMSS

Phenol ionisation depends on the $\mathrm{pH}$ value and the ionic fraction of the phenolate ion ( $\phi_{\text {ionic }}$ ). The phenolate ion can be

calculated using the following equation [14]. $\phi_{\text {ion }}=\frac{1}{1+10^{p K a-p H}}$.

As $\mathrm{pH}$ increases $\phi_{\text {ion }}$ increases and, therefore, the $\mathrm{pH}$-dependent nature of phenol adsorption could be explained by the fact that only the phenol molecules adsorb effectively onto surfaces of AMSS and CMSS through van der Waals interaction whereas, the phenolate anions do not owing to their hydrophilic nature. The surface of UAMSS was protonated at low $\mathrm{pH}$ values hence strong electrostatic forces of attraction with the negatively charged phenolate. Phenol has $\mathrm{pK}_{\mathrm{a}}$ value of 10 at $25^{\circ} \mathrm{C}$, hence at high $\mathrm{pH}$ values it behaves as an anion. Adsorption at higher $\mathrm{pH}$ was less due to repulsion [3]. Competition occurs between the $\mathrm{OH}^{-}$ions and the phenol molecules for sorption sites [15].

\subsection{Effect of adsorbent dose on phenol Removal}

This adsorbent dose determines the capacity of UAMSS for a given phenol concentration. This can furnish the phenol adsorbate-adsorbent equilibrium systems. The phenol uptake per unit mass decreased with the increase in adsorbent dose (Figure 4) ranging from 1.8 - $9.0 \mathrm{mg} / \mathrm{g}$ for UMASS. This trend may be explained based on mass balance relationship in equation (3) [6]. At increasingly high sorbent dosages $(0.5-2.5 \mathrm{~g})$, fixed initial concentration (100 mg/L) and fixed aliquot volume $(50 \mathrm{~mL})$, the available phenol molecules are unable to cover all the exchangeable sites on the biosorbent, resulting in low phenol uptake at high dosage $[15,3]$.

Finally, phenol removal efficiencies expressed as a function of only the initial and final concentration of phenol, on the other hand, increase with increase with adsorbent dosage. 


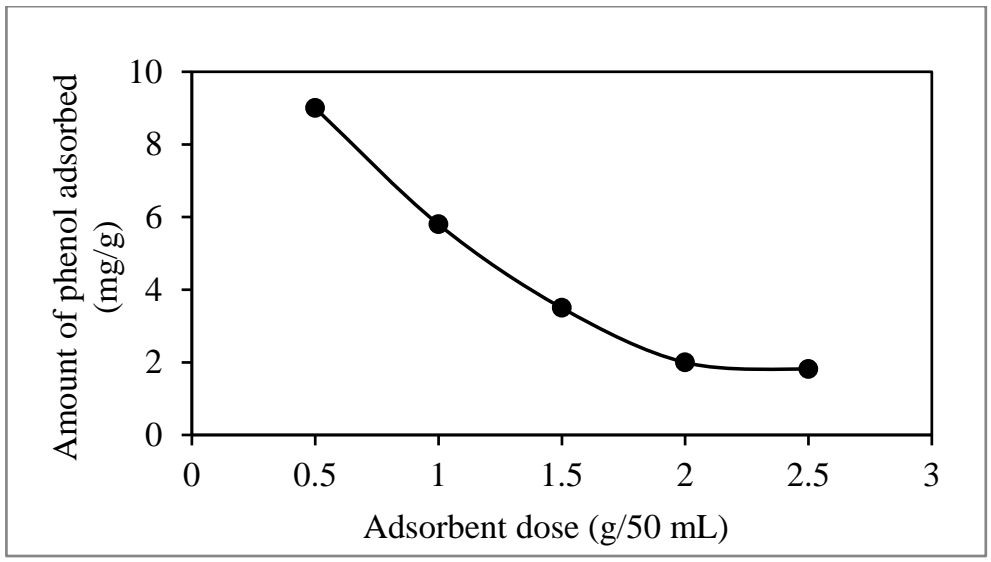

Figure 4 Effect of adsorbent dose on phenol adsorption onto un-activated adsorbent UAMSS

\subsection{Adsorption Kinetics}

Contact time is an important parameter to determine the equilibrium time of adsorption process [17]. The characteristics of Moringa oleifera seed shells and its available sites affected the time needed to reach equilibrium [24]. In this study, rate curve for aqueous phase removal of phenol on UAMSS is illustrated in Figure 5.

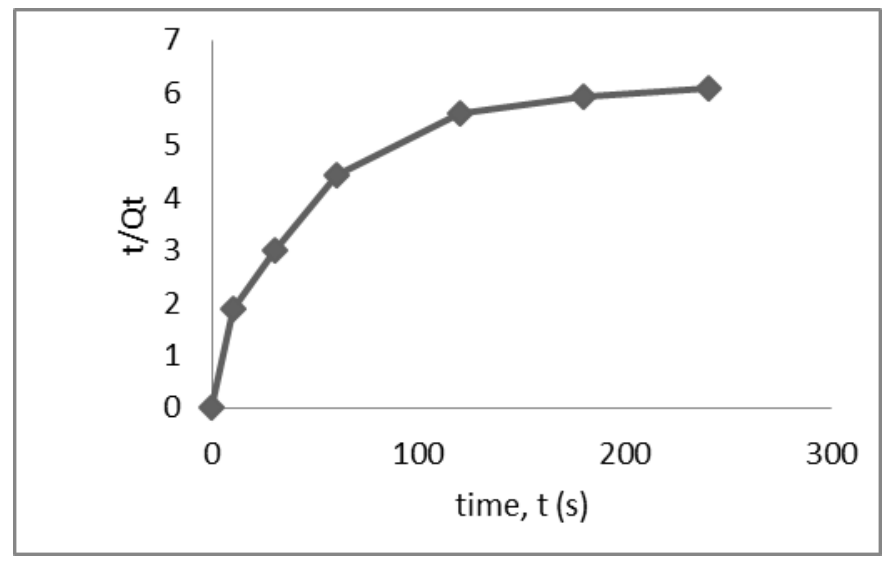

Figure 5 Rate curve of phenol adsorption onto un-activated adsorbent UAMSS

For adsorbent UAMSS, phenol uptake increased very rapidly within the first $50 \mathrm{~min}$ but slowed down beyond this point, gradually phenol uptake was not increased significantly signifying that the process would not offer additional kinetic advantage when contact times longer than 4 hour were employed. The uptake of phenol diminished as equilibrium point was attained.Experimental data for the aqueous phase removal of phenol on UAMSS as a function of contact time were fitted into the Lagergren Pseudo-first- order and Blanchard pseudo-second-order kinetic models given by Equations (6) and (7), respectively.

$$
\begin{aligned}
& \ln \left(Q_{e}-Q_{t}\right)=\ln Q_{e}-k_{1} t \\
& \frac{t}{Q_{t}}=\frac{1}{k_{2} Q_{e}^{2}}+\frac{t}{Q_{e}}
\end{aligned}
$$

Where Qe and Qt (mg/g), refers to the amounts of phenol adsorbed on the adsorbent un-activated carbon at equilibrium and at a specified time, $\mathrm{t}(\mathrm{min}) . \mathrm{k} 1$ (min-1) and $\mathrm{k} 2$ (g/mg.min) are the pseudo-first and pseudo-second-order kinetic are the adsorption rate constant respectively. Figures 6 and 7 represent the plots derived by the corresponding models while Table 2 records the kinetic parameters so generated. 


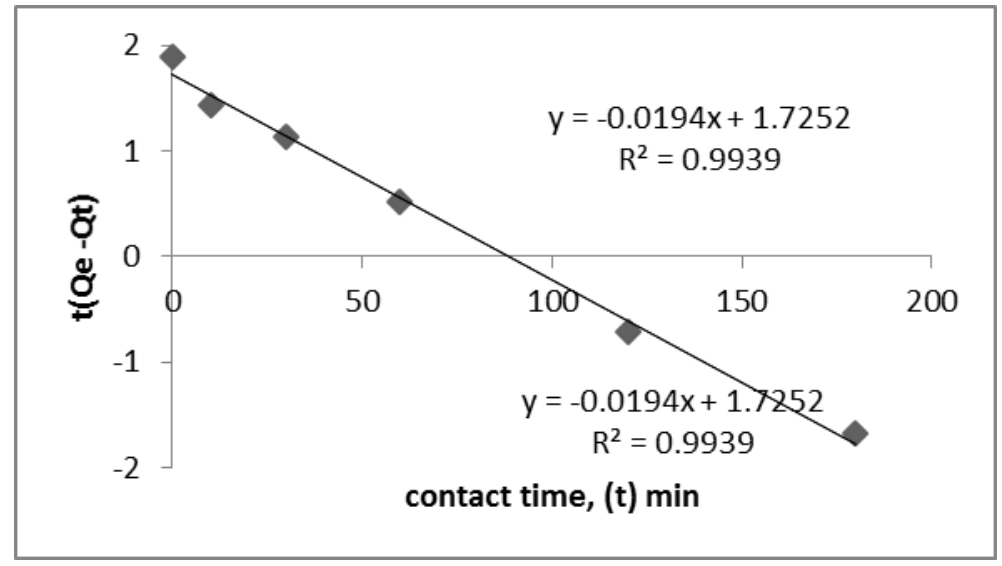

Figure 6 Pseudo-first-order kinetic for phenol adsorption onto un-activated adsorbent UAMSS

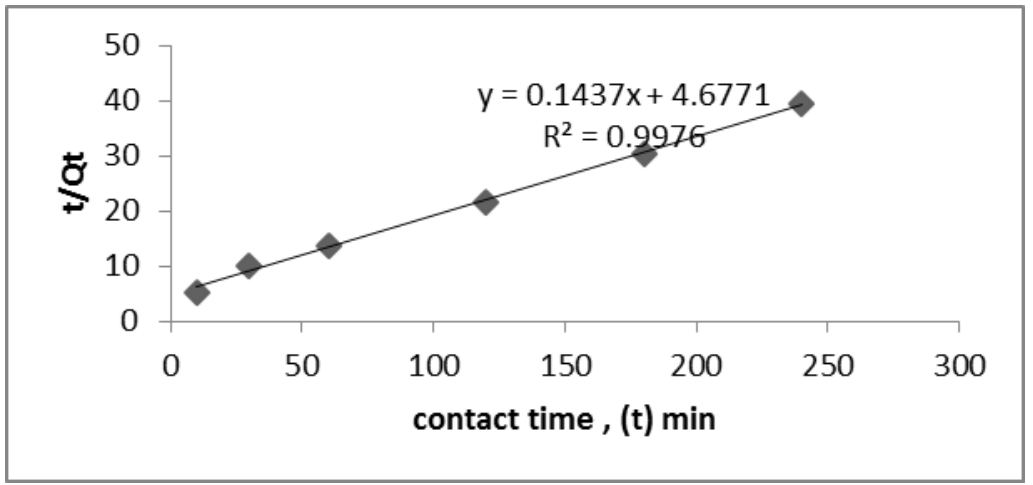

Figure 7 Pseudo-second-order kinetic for phenol adsorption onto un-activated adsorbent UAMSS

Considering the phenol-UAMSS sorption system, based on the coefficient of determination, $R^{2}$ as seen from Table 2 therefore, the pseudo-second order model recorded the higher values $\left(R^{2}\right.$ 0.997).relative to the pseudo-first-order kinetic model.

Table 2 Kinetic parameters for phenol adsorption onto un-activated Moringa oleifera seed shells adsorbent @25ㄷ

\begin{tabular}{|l|l|l|}
\hline Adsorbent & Lagergren Parameters & Blanchard Parameters \\
\hline UAMSS & $\mathrm{k} 1$ (min-1) 0.019 & K2 (g/mg.min) 4.37x10-3 \\
\hline & R2 0.993 R2 0.997 & \\
\hline
\end{tabular}

\subsection{Equilibrium adsorption capacities and isotherm profiles}

Equilibrium data from adsorption experiments are usually presented in the form of an isotherm, which graphically displays the ratio of sorbed to non-sorbed solute per unit mass of the adsorbent at constant temperature. Figure 8 display the isotherms for the aqueous phase adsorption of phenol on UAMSS adsorbent. At operating initial phenol concentration $(20 \leq \mathrm{Ce} \leq 100 \mathrm{mg} \mathrm{L}-1)$ Removal efficiencies RE (\%) UAMSS (50.29 $\leq \mathrm{RE}(\%) \leq 78.15)$ were calculated from the equilibrium adsorption data as the percent of phenol removed. Corresponding equilibrium adsorption capacities, Qe (mg g-1) for UAMSS: $250 \mathrm{C}(2.10 \leq \mathrm{Qe} \leq 6.98)$. The isotherm profiles are also noteworthy because they can provide information regarding the nature and intensity of sorption for a particular adsorbate-adsorbent system.

The isotherms for UAMSS is somewhat L-shaped indicating that the intermolecular forces of phenol are comparatively weaker than the sorptive forces, which implies that the activation energy of adsorption is independent of surface coverage for optimum removal [21]. 


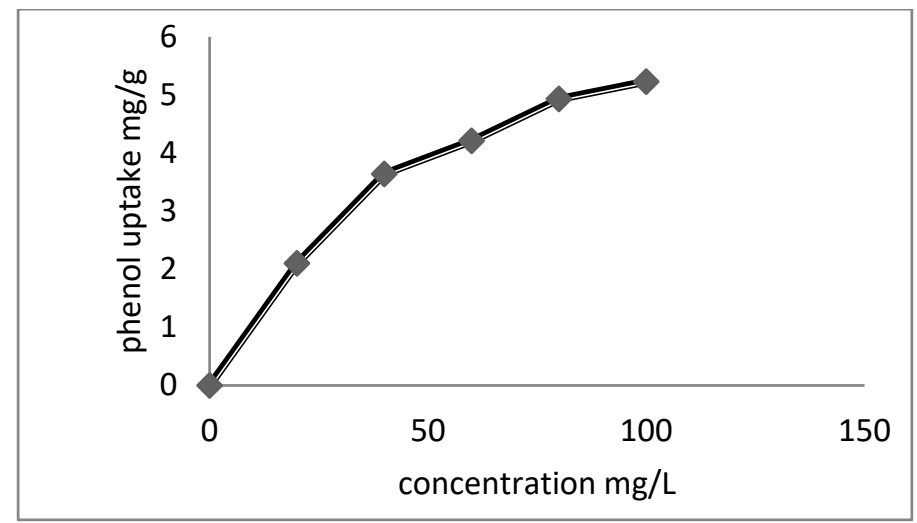

Figure 8 Isotherm profile for aqueous phase removal of phenol onto un-activated adsorbent UAMSS

Equilibrium data for the adsorption of phenol from aqueous phase on UAMSS were fitted into the linearized form of the Langmuir and Freundlich isotherm models represented by

Equation (8) and (9), respectively.

$\frac{C}{Q}=\frac{C}{Q_{\max }}+\frac{1}{K_{L} Q_{\max }}$

$\ln Q_{e}=\frac{1}{n_{F}} \ln C_{e}+\ln K_{F}$

Were $\mathrm{Q}$ is the equilibrium amount of phenol adsorbed per unit mass of the adsorbent $(\mathrm{mg} / \mathrm{g})$, and $\mathrm{C}$ is the residual concentration $(\mathrm{mg} / \mathrm{g})$. is the maximum amount of phenol adsorbed per unit mass of adsorbent $(\mathrm{mg} / \mathrm{g}$ ) corresponding to complete coverage of adsorptive sites, $\mathrm{KL}(\mathrm{L} / \mathrm{mg})$ is the Langmuir constant related to the energy of adsorption. $\mathrm{KF}$ is Freundlich constant (mg1-1/nL1/n/g), related to the adsorption capacity and $\mathrm{nF}$ is a dimensionless empirical parameter related to the adsorption intensity which varies with heterogeneity of the material [25]. A linear plot of C/Q versus $\mathrm{C}$ gives the inverse of the slope as and $\mathrm{KL}$ is derived from the intercept; while a linear plot of $1 \mathrm{nQ}$ versus $1 \mathrm{nC}$ gives the inverse of the slope as $\mathrm{nF}$ and intercept as KF. The Langmuir and Freundlich isotherm plots are presented in Figure 9 and 10. The corresponding model parameters are recorded in Table 3.

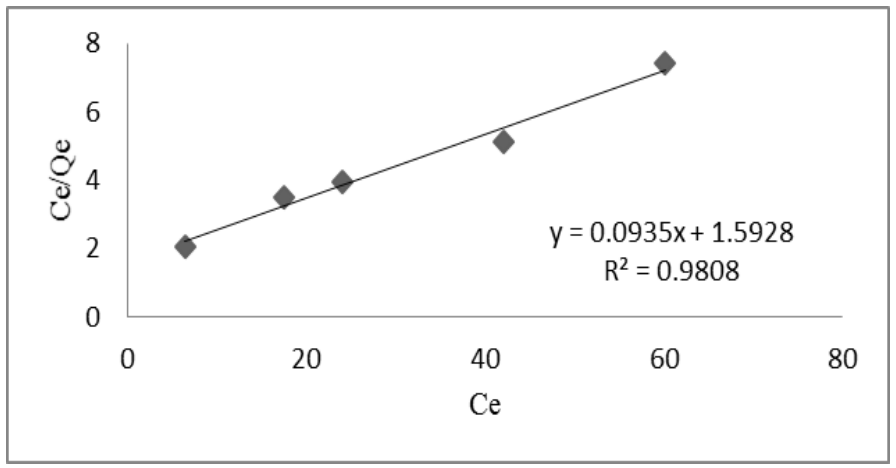

Figure 9 Linearized Langmuir isotherms for adsorption of phenol onto adsorbent UAMSS

Conformation of the experimental data into Langmuir isotherm model indicates the homogeneous nature of M. oleifera adsorbents UAMSS surface, i.e. each phenol molecule /M. oleifera adsorbent adsorption has equal adsorption activation energies [13]. The characteristic of the Langmuir isotherm are determined by the dimensionless constant called separation factor, RL expressed as:

$\mathrm{RL}=1 /(1+\mathrm{KL} . \mathrm{Co})$ 
Were KL (L/mg) and Co (mg/L) retained their usual meaning as stated in equation (8). RL indicates the nature of the adsorption process as follows: $\mathrm{RL}>1$, unfavorable, $\mathrm{RL}=1$, Linear, $0<\mathrm{RL}$, Favorable, $\mathrm{RL}=0$, Irreversible. The RL value recorded in the range of 0 -1in this study is indicative of favorable adsorption for adsorbent UMASS. Similar observation was reported by removal of phenol from aqueous solution by adsorption on yeast Saccharomyces cerevisiae [13], and by the adsorption of phenol from aqueous media by an agro-waste Hemidesmus indicus based activated carbon [20] and potential of tendu leaf for phenol removal in aqueous systems [12].

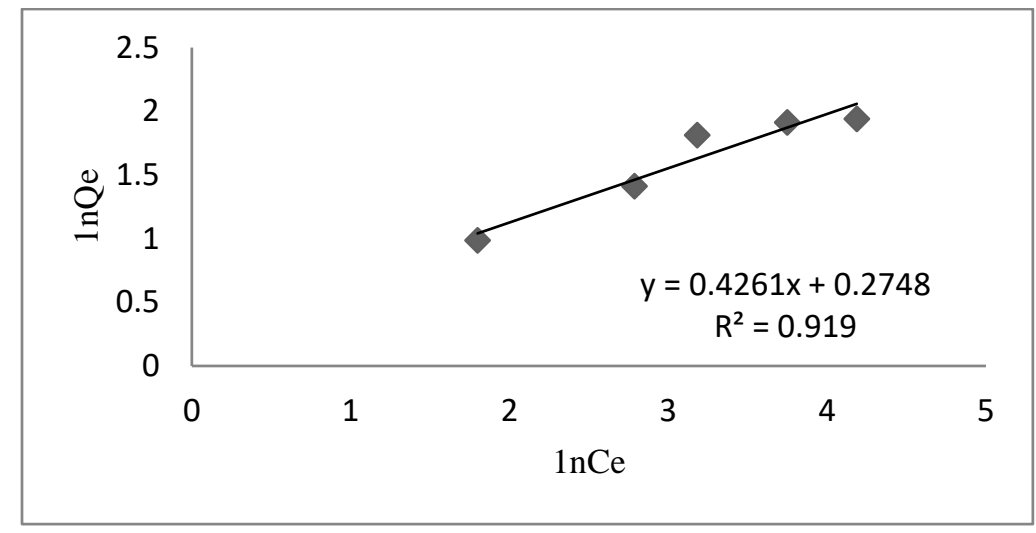

Figure 10 Linearized Freundlich isotherms for adsorption of phenol onto adsorbent UAMSS

The Freundlich isotherm models propose that adsorbent surface is heterogeneous in nature, and that energies are distributed at active sites on the adsorbent surface, this is accompanied by the interaction between adsorbed molecules. From Table 3, the higher KF Freundlich constant value shows easy phenol uptake from the aqueous solution. Also the higher value of $\mathrm{nF}$ reflects the intensity of adsorption hence signifies that the biosorbent surfaces is heterogeneous in nature and high enough for effective separation [21].

Table 3 Isotherm parameters for phenol adsorption onto un-activated Moringa oleifera seed shells adsorbent @25ㄷ

\begin{tabular}{|c|c|c|c|}
\hline Adsorbent & Langmuir Parameters & Freundlich Paramete & \\
\hline \multirow[t]{4}{*}{ UAMSS } & Qo $(\mathrm{mg} / \mathrm{g}) \quad 6.95$ & $\mathrm{KF}$ (mg1-1/nL1/ng-1) & 1.295 \\
\hline & KL (L.mg-1) 0.0584 & $\mathrm{nF}$ & 2.347 \\
\hline & 0.2551 & R2 & 0.919 \\
\hline & 0.980 & & \\
\hline
\end{tabular}

Table 4 Summary of Selected Studies on Phenol Adsorption by Adsorbents

\begin{tabular}{|l|l|l|}
\hline Biosorbent & Qo (mg/g) & Reference \\
\hline Organobentonite & 38 & {$[20]$} \\
\hline Dry sewage sludge & 16 & {$[18]$} \\
\hline Tendu leaf & 8 & {$[12]$} \\
\hline Saccharomyces cerevisiae & 27 & {$[13]$} \\
\hline Ammonium chloride-Treated Moringa & & \\
\hline oleifera seed shells & 10 & {$[10]$} \\
\hline Carbonized Moringa oleifera Seed Shells & 13 & {$[10]$} \\
\hline Un-activated Moringa oleifera seed shell 6.95 this study & & \\
\hline
\end{tabular}




\section{Conclusion}

Un-activated adsorbent prepared in this study showed good physicochemical attribute and adsorptive behavior towards phenol removal. The equilibrium data fitted very well with Langmuir isotherm as per phenol uptake. Adsorption kinetics obeyed the Blanchard pseudo-second-order kinetic model. From all indication, these adsorbent when used in a large scale may find potential use in phenol removal from aqueous effluents and wastewater.

\section{Compliance with ethical standards}

\section{Acknowledgments}

Authors are thankful to the Head, chemistry department federal university of Agriculture-Makurdi for providing necessary laboratory facilities for the physicochemistry analysis. And also to the management staff of the Kaduna environmental protection authority- Nigeria for providing bench space and some facilities for adsorption analysis, NARECT Zaria for FTIR analysis.

\section{Disclosure of conflict of interest}

There are no conflict of interests.

\section{References}

[1] Öberg T. Halogenated aromatics from steel production: results of a pilot-scale investigation. Chemosphere. 2004 Aug 1; 56(5):441-8.

[2] Rengaraj S, Moon SH, Sivabalan R, Arabindoo B, Murugesan V. Agricultural solid waste for the removal of organics: adsorption of phenol from water and wastewater by palm seed coat activated carbon. Waste management. 2002 Aug 1; 22(5):543-8.

[3] Okoye AI, Ejikeme PM, Onukwuli OD. Lead removal from wastewater using fluted pumpkin seed shell activated carbon: Adsorption modeling and kinetics. International Journal of Environmental Science \& Technology. 2010 Sep 1; 7(4):793-800.

[4] USEPA, Ambient Water Quality Criteria DOC: Phenol, US EPA-440/5-80-066 (PB 81-117772), 1980; 1100 - 1156.

[5] ATSDR, Toxicological Profile for phenol. Atlanta, GA: U.S. Department of Health and Human Services, Public Health Service 1998.

[6] Lanouette, K..H., Treatment of Phenolic Wastes. - Chemical Engineering. 1977; 84 (22):99 -106.

[7] Mustafa, M.R. Sarma, S.E. and Yusuf, A.M. Removal of Organic Pollutants from Aqueous Solution. Part-1, Adsorption of Phenol by Activated Carbon. - Indian Journal of Chemistry. 1989; 28A:94 - 98.

[8] Street, M.J. Patrick W. and Camporroperez, M.J. Sorption of phenol and p-Chlorophenol from water using conventional and novel activated carbons. Water Science. Resources, 1995; 29:467.

[9] Wuana, R.A. Okieimen, F.E. Adejo, S.O. and Mbasugh, P.A. Single and competitive aqueous phase adsorption of calcium and magnesium ions onto rice husk carbon, Journal of Chemical Society of Nigeria, 2009; 34(1):97 - 109.

[10] Wuana, R.A. Nnamonu, L.A. and Idoko, J.O. Sorptive Removal of Phenol from Aqueous Solution by Ammonium Chloride-Treated and Carbonized Moringa oleifera Seed Shells; International Journal of Science and Research, 2015; 4(6):594 - 602.

[11] Ahmedna, N. Marshall, M. and Rao. M. Production of granular activated carbon from selected agricultural by products. Bioresource Technology, 2000; 1(2):113 - 123.

[12] Shoemaker, D.P. Garland, C.W. and Nibbler, J.W. Experiments in Physical Chemistry, Mc-Graw-Hill Publishing Company, NY; 353, 1989.

[13] Nagda, G. K. Diwan, A. M. and Ghole, V. S. Potential of Tendu leaf refuse for phenol in aqueous system, Applied Ecology and Environmental Research. 2007; 5 (2):1 - 9.

[14] Idoko, J.O. Wuana R. A. and W O. Musa. Assessment of Heavy Metal Levels in Juji River Water and Catchment Soil in Kaduna City, Nigeria: Journal of Chemical Society of Nigeria 2016; 41(1):49 - 52. 
[15] Idoko, J.O. Determination of $\beta$ - carotene from local vegetables: Zogale leaf Moringa oleifera, Red sorrel calyx Hibiscus Sabdarifa and Dinya leaf Vitex doniana; Journal of Environmental Science, Toxicology and food Technology, 2014;8(11):p.08-10

[16] Moyo, M. Eusebia, M. Fidelis, C. And Nyamunda C. Removal of phenol from aqueous solution by adsorption on yeast, Saccharomyces cerevisiae International Journal of Research and Reviews in Applied Sciences. $2012 ; 11$ (3):486 - 494 .

[17] Qadeer, R. and Rehan, A.H. A Study of the Adsorption of Phenol by activated Carbon from Aqueous Solution, Turkish Journal of Chemistry, 2002; 26:57 - 361.

[18] Banat, F. Al-Bashir, B. Al-Asheh, S. and Hayajneh, O. Adsorption of phenol by bentonite. Environmental pollution, 2000; 107:391 - 398.

[19] Uddin, M.T. Islam, M.S, and Abedin, M.Z. Adsorption of phenol from aqueous solution by water hyacinth ash. Journal of Engineering and Applied Science, 2007; 2(2):11 - 1.

[20] Srihari, V. and Ashutosh, D. Study on Adsorption of Phenol from Aqueous Media Using Extracted Residue of Hemidesmus indicus. - Asian Journal of Microbiology, Biotechnology and Environmental Science 2005; 7(3):469 -472 .

[21] Thowornchaisist, V. and Pakulanon, K. Application of Dried Sewage Sludge as Phenol Biosorbent. Biological Technology. 2007; 98:140 - 144 .

[22] Srihari, V. and Das, A. Adsorption of Phenol from Aqueous Media by an Agro Waste (Hemidesmus indicus) Based Activated Carbon. Applied Ecology and Environmental Research. 2009; 7 (1):13-23.

[23] Rawajfih, Z. and Nsour, N. Characteristics of Phenol and Chlorinated Phenols Sorption onto Surfactant Modified Bentonites. Journal of Colloid and Interface Science. 2006; 298:39 - 49.

[24] Kennedy, L.J, Vijaye, J.J, Kayalvizhi, K, and Sekaran G. Adsorption of phenol from aqueous solution using mesoporous carbon prepared by two-stage process. Chemical Engineering Journal 2007; 132:279 - 287.

[25] Martinez M., Torres M., Guzman, Guzman, C. and Maestri. D. Preparation and Characterization of Activated Carbon from olive Stones and Walnut Shells. Journal of Industrial Crops and Products. 2006; 23(1):23 - 28.

[26] American Water Works Association (AWWA) Standards for Granular Activated Carbon, NSI/AWWA 1991; B60490: Denver Co.p. 117 - 124.

[27] Nwonsu O. F., Olu-Owolabi I. B., Adebowale B.I, Henle K.O.T. and Schwarzebbolz U. Pore Structure and Surface Functional Groups on Six Tropical Fruit Nutshell Active Carbons. Journal of Bioremediation, Biodiversity and Bioavailability. 2009; 3 (2):89-95.

[28] A. Maghraby and N. A. Taha Equilibrium and kinetic studies for the removal of cationic dye using banana pith, Advances in Environmental Research 2014; 3:217 - 230. 